\title{
Clinicopathologic and molecular spectrum of RNASEH1-related mitochondrial disease
}

\section{OPEN}

Enrico Bugiardini, MD Olivia V. Poole, MRCP Andreea Manole, BSc Alan M. Pittman, PhD Alejandro Horga, MD Iain Hargreaves, $\mathrm{PhD}$ Cathy E. Woodward, BSc Mary G. Sweeney, BSc Janice L. Holton, FRCPath, PhD Jan-Willem Taanman, $\mathrm{PhD}$

Gordon T. Plant, FRCOphth, MD Joanna Poulton,

FRCPCH, DM

Massimo Zeviani, MD, $\mathrm{PhD}$

Daniele Ghezzi, PhD

John Taylor, PhD

Conrad Smith, PhD

Carl Fratter, MPhil

Meena A. Kanikannan, MD

Arumugam Paramasivam, $\mathrm{PhD}$

Kumarasamy Thangaraj, $\mathrm{PhD}$

Antonella Spinazzola, MD Ian J. Holt, PhD

Henry Houlden, FRCP, $\mathrm{PhD}$

Michael G. Hanna, FRCP, MD

Robert D.S. Pitceathly, MRCP, PhD

Correspondence to Dr. Pitceathly: r.pitceathly@ucl.ac.uk

Supplemental data at Neurology.org/ng

\section{ABSTRACT}

Objective: Pathologic ribonuclease H1 (RNase H1) causes aberrant mitochondrial DNA (mtDNA) segregation and is associated with multiple mtDNA deletions. We aimed to determine the prevalence of RNase $\mathrm{H} 1$ gene (RNASEH1) mutations among patients with mitochondrial disease and establish clinically meaningful genotype-phenotype correlations.

Methods: RNASEH1 was analyzed in patients with (1) multiple deletions/depletion of muscle mtDNA and (2) mendelian progressive external ophthalmoplegia (PEO) with neuropathologic evidence of mitochondrial dysfunction, but no detectable multiple deletions/depletion of muscle mtDNA. Clinicopathologic and molecular evaluation of the newly identified and previously reported patients harboring RNASEH1 mutations was subsequently undertaken.

Results: Pathogenic c.424G>A p.Val142Ile RNASEH1 mutations were detected in 3 pedigrees among the 74 probands screened. Given that all 3 families had Indian ancestry, RNASEH1 genetic analysis was undertaken in 50 additional Indian probands with variable clinical presentations associated with multiple mtDNA deletions, but no further RNASEH1 mutations were confirmed. RNASEH1-related mitochondrial disease was characterized by PEO (100\%), cerebellar ataxia (57\%), and dysphagia (50\%). The ataxia neuropathy spectrum phenotype was observed in 1 patient. Although the c.424G>A p.Val142lle mutation underpins all reported RNASEH1related mitochondrial disease, haplotype analysis suggested an independent origin, rather than a founder event, for the variant in our families.

Conclusions: In our cohort, RNASEH1 mutations represent the fourth most common cause of adult mendelian PEO associated with multiple mtDNA deletions, following mutations in POLG, RRM2B, and TWNK. RNASEH1 genetic analysis should also be considered in all patients with POLG-negative ataxia neuropathy spectrum. The pathophysiologic mechanisms by which the c.424G $>$ A p.Val142lle mutation impairs human RNase H1 warrant further investigation. Neurol Genet 2017;3:e149; doi: 10.1212/NXG.0000000000000149

\section{GLOSSARY}

COX = cytochrome c oxidase; IBD = identity by descent; $\mathbf{m t D N A}=$ mitochondrial DNA; $\mathbf{N C S}=$ nerve conduction studies; PCA = principal component analysis; PEO = progressive external ophthalmoplegia; RNase H1 = ribonuclease H1; RRF = ragged red fiber.

Mitochondrial diseases are commonly inherited disorders caused by mutations in nuclear and mitochondrial DNA (mtDNA). Dysfunction in a subset of nuclear genes involved with mtDNA maintenance results in the secondary accumulation of multiple deletions and/or depletion of muscle mtDNA. ${ }^{1}$ The clinical spectrum of this group of disorders is broad,

From the MRC Centre for Neuromuscular Diseases (E.B., O.V.P., A.M., A.H., J.L.H., H.H., M.G.H., R.D.S.P.), UCL Institute of Neurology and National Hospital for Neurology and Neurosurgery; Department of Molecular Neuroscience (A.M., A.M.P., J.L.H., H.H., M.G.H.), Division of Neuropathology (J.L.H.), Department of Clinical Neuroscience (J.-W.T., A.S., I.J.H.), UCL Institute of Neurology; Neurometabolic Unit (I.H.), Neurogenetics Unit (C.E.W., M.G.S.), Department of Neuro-ophthalmology (G.T.P.), National Hospital for Neurology and Neurosurgery, London; Nuffield Department of Obstetrics and Gynaecology (J.P.), University of Oxford; MRC-Mitochondrial Biology Unit (M.Z.), Cambridge, UK; Unit of Molecular Neurogenetics (D.G.), Fondazione IRCCS Istituto Neurologico "Carlo Besta," Milan, Italy; Oxford Medical Genetics Laboratories (J.T., C.S., C.F.), Oxford University Hospitals NHS Foundation Trust, Churchill Hospital, UK; Department of Neurology (M.A.K.), Nizam's Institute of Medical Sciences; CSIR-Centre for Cellular and Molecular Biology (A.P., K.T.), Hyderabad, Telangana, India; MRC Mill Hill Laboratory (I.J.H.), London, UK; Biodonostia Research Institute (I.J.H.), San Sebastián, Spain; and Department of Basic and Clinical Neuroscience (R.D.S.P.), Institute of Psychiatry, Psychology and Neuroscience, King's College London, UK.

Funding information and disclosures are provided at the end of the article. Go to Neurology.org/ng for full disclosure forms. The Article Processing Charge was funded by the Medical Research Council.

This is an open access article distributed under the terms of the Creative Commons Attribution License 4.0 (CC BY), which permits unrestricted use, distribution, and reproduction in any medium, provided the original work is properly cited. 
ranging from severe infantile hepatocerebral syndromes to benign, late-onset progressive external ophthalmoplegia (PEO). Mutations in the mtDNA maintenance gene RNASEH1, encoding ribonuclease H1 (RNase H1), have recently been linked to adult mitochondrial disease presenting with CNS and neuromuscular involvement. ${ }^{2}$ RNase $\mathrm{H} 1$ degrades RNA hybridized to $\mathrm{DNA}^{3}$ and knockout mice suffer embryonic lethality owing to mtDNA depletion, ${ }^{4}$ attributable to persistent mtDNA RNA/DNA hybrids. ${ }^{5}$ However, humans with RNASEH1 mutations develop a relatively mild clinical syndrome, comprising adultonset PEO associated with multiple mtDNA deletions secondary to the impaired physical segregation of $\mathrm{mtDNA}$ molecules. ${ }^{6}$ The prevalence and clinical spectrum of RNASEH1related mitochondrial disease is currently unknown.

We screened 74 unrelated probands with genetically undetermined mitochondrial disease for RNASEH1 mutations. The previously reported pathogenic missense transition c.424G $>$ A p.Val142Ile was detected in 3 families with Indian ancestry: homozygous mutations were confirmed in 2 pedigrees and compound heterozygous mutations in combination with a novel c.442T $>C$ p.Cys148Arg variant in a third. Detailed clinicopathologic and molecular profiling of these newly identified families harboring RNASEH1 mutations, and evaluation of all previously reported cases, was subsequently undertaken to determine the phenotypic spectrum of RNASEH1-mediated mitochondrial disease and establish clinically meaningful genotype-phenotype correlations. Finally, the ancestral origins of the "common" RNASEH1 c.424G $>$ A p.Val142Ile mutation were investigated.

METHODS Participants. Patients referred to the London and Oxford NHS England nationally commissioned service for mitochondrial diseases were recruited to the study according to the following criteria: (1) confirmed multiple deletions/depletion of muscle mtDNA and (2) mendelian PEO with pathologic evidence of mitochondrial dysfunction, including ragged red fibers (RRFs) and/or cytochrome $c$ oxidase (COX)-negative muscle fibers, without detectable multiple deletions or depletion of muscle mtDNA. RNASEH1 genetic analysis was also undertaken in a cohort of Indian patients with evidence of multiple mtDNA deletions detectable in muscle.
Genetic studies. Whole-exome and Sanger sequencing was used to analyze the 8 coding exons and intron-exon boundaries of RNASEH1 (primer sequences available on request).

Clinicopathologic and molecular evaluation of patients. Patients harboring RNASEH1 mutations were assessed clinically by the authors. Medical records and muscle tissue histopathologic and electron microscopy findings were reviewed. Real-time quantitative PCR of DNA extracted from muscle was undertaken in all patients harboring RNASEH1 mutations and multiple mtDNA deletions to exclude coexisting mtDNA depletion. Previously published RNASEH1 variants (pathogenic and of unknown significance) were evaluated ${ }^{2,7}$ and clinicopathologic and genotypic data extracted and combined with the LondonOxford cohort to accurately define the clinical genetic spectrum of all known RNASEH1-mediated mitochondrial disease.

Principal component analysis, identity by descent, and haplotyping. Principal component analysis (PCA), using GCTA software (version 1.26.0), was performed relative to the HapMap project populations (CEU, JPT, and YRI) to study the geographical origin of 2 Indian families where exome-sequencing data were available (families A and B). Identity by descent (IBD) analysis was utilized in plink software ( $11.90 \mathrm{blg})$ to explore the possibility of a common lineage for the pedigrees. Haplotyping was adopted to investigate the possibility of a common origin for the c.424G $>$ A p.Val142Ile mutation. Six single nucleotide variants extracted from available exome data were used to construct haplotypes around the mutation site, and Sanger sequencing of the variants in affected individuals from the London-Oxford cohort and in 2 previously reported families was undertaken. ${ }^{6}$ Haplotypes were phased around homozygous variant sites only, given parental samples were unavailable.

Standard protocol approvals, registrations, and patient consents. The study was approved and performed under the ethical guidelines issued by our institutions for clinical studies, with written informed consent obtained from all participants for genetic studies.

RESULTS RNASEH1 sequence data analysis. Seventyfour unrelated probands were recruited from the London and Oxford NHS England nationally commissioned service for mitochondrial diseases and categorized as follows: multiple deletions $(\mathrm{n}=33)$ and depletion $(n=21)$ of muscle mtDNA and mendelian PEO with neuropathologic evidence of mitochondrial dysfunction, but no detectable multiple deletions/depletion of muscle mtDNA ( $\mathrm{n}=20$ ). Homozygous RNASEH1 c. $424 \mathrm{G}>\mathrm{A}$ p.Val142Ile mutations were identified in 2, apparently unrelated, nonconsanguineous families (family A: A-III.8, A-III.9, A-III.10, and A-III.11; and family B: B-II.1 and B-II.8), and a third singleton case (family C: C-II.1) was compound heterozygous with the novel missense mutation c. $442 \mathrm{~T}>\mathrm{C}$ p.Cys148Arg (figure 1A). Parental segregation was confirmed. All 3 families had Indian ancestry. Affected individuals harbored multiple deletions of muscle mtDNA. Fifty additional unrelated Indian probands with multiple deletions of muscle mtDNA deletions were screened for RNASEH1 mutations 
A

$$
\text { A }
$$

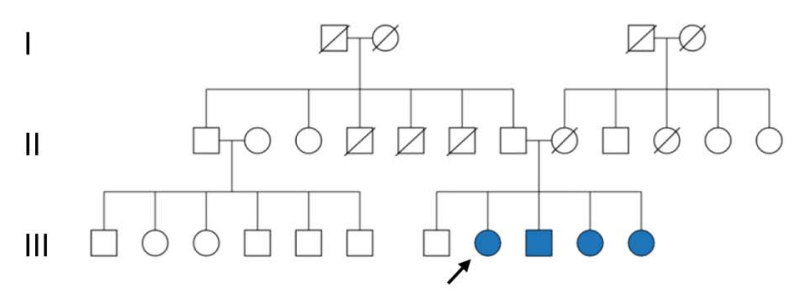

Family A

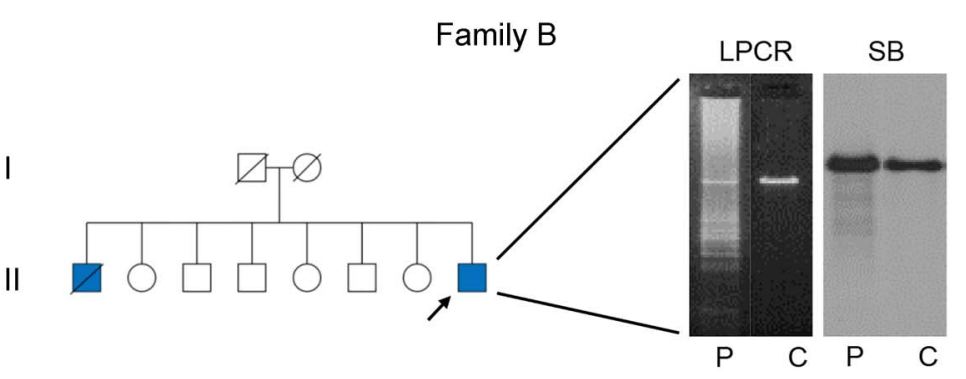

Family C

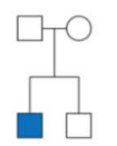

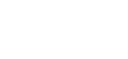
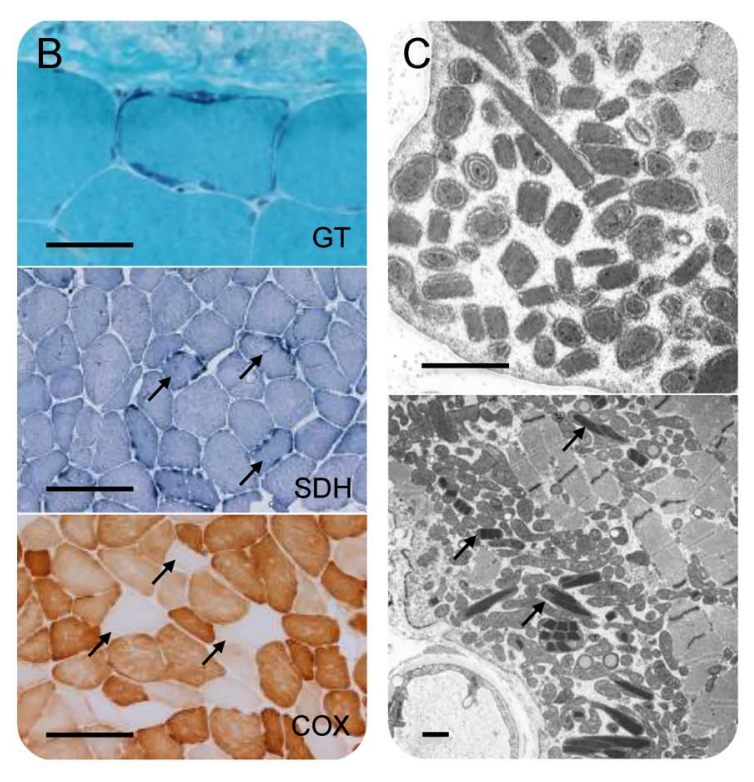

(A) Pedigrees of families harboring RNASEH1 mutations. Filled blue symbols represent affected individuals. Arrows indicate probands. Long range PCR (LPCR) and Southern blot (SB) demonstrate multiple deletions of muscle mitochondrial DNA (B-II.8) in patient (P) when compared with control muscle (C). (B) Muscle biopsy histology (A-III.8) demonstrating ragged red fibers (modified Gomori trichrome, GT), ragged blue fibers (succinate dehydrogenase, SDH), and several muscle fibers deficient in cytochrome $c$ oxidase (COX), arrows. Scale bar represents $50 \mu \mathrm{m}$ in GT and $200 \mu \mathrm{m}$ in SDH and COX. (C) Ultrastructural examination (A-III.8) showing increased numbers of mitochondria, many of which are structurally abnormal, including the presence of paracrystalline inclusions, arrows. Scale bar represents $1 \mu \mathrm{m}$.

(see table e-1 at Neurology.org/ng, for clinicopathologic spectrum), but no known or novel RNASEH1 variants were detected.

Clinicopathologic and molecular features in RNASEH1 mutations. Mean age of symptom onset in the London-Oxford cohort was 29 years (range, 13-36 years). All patients presented with either ptosis or imbalance. The clinical phenotype was characterized by PEO, proximal muscle weakness, and cerebellar ataxia. One patient had a sensory ataxic neuropathy, with nerve conduction studies (NCS) and EMG indicative of a nonlength-dependent, predominantly sensory, axonal neuropathy. Brain MRI demonstrated moderate generalized parenchymal volume loss $(n=2)$. Histopathologic examination of muscle revealed RRFs and COX-negative fibers in all cases examined, while ultrastructural examination showed increased and abnormal mitochondria, many with paracrystalline inclusions (figure 1, B and C). There was no evidence of a coexisting reduction in muscle mtDNA copy number (B-II.8 and C-II.1).

Three families (6 affected individuals) with confirmed RNASEH1 mutations have previously been reported. ${ }^{2}$ An additional case was identified from variants of unknown significance published in exomesequencing studies. ${ }^{7}$ These data were combined with the London-Oxford cohort and confirmed that PEO was a universal feature in patients with RNASEH1related mitochondrial disease and that a substantial proportion of patients (57\%) exhibited cerebellar dysfunction. Additional clinical features (summarized in table 1) included dysphagia (50\%), proximal muscle weakness (36\%), peripheral neuropathy (36\%), and pyramidal signs (14\%). NCS and EMG were consistent with involvement of motor and/or sensory nerve fibers with demyelinating, axonal, or ganglionic features. RRFs and/or COX-deficient fibers and multiple mtDNA deletions were reported in all cases when muscle tissue was available.

The c.424G $>$ A p.Val142Ile mutation was detected in all 7 families (both newly reported and previously published). Three were homozygous and 4 were compound heterozygous with the following mutations: c.442T $>$ C p.Cys148Arg $(\mathrm{n}=2)$, c. $469 \mathrm{C}>\mathrm{T}$ p.Arg157*, and c.554C $>$ T p.Ala185Val.

PCA, IBD, and haplotyping. PCA revealed that families $A$ and $B$ clustered to the same ethnic group (figure 2A, top panel), while IBD analysis implied a distant relationship to approximately second cousins (mean PI_HAT $0.049 \pm 0.013$ ). Haplotyping of families A and B suggested one shared founder haplotype of $3.67 \mathrm{Mb}$ which was also present in family C. However, given that the c. $424 \mathrm{G}>$ A p.Val142Ile variant was heterozygous, it was not possible to decipher whether this represented a population-specific or an ancestral mutation (figure 2A, bottom panel). Analysis of the same haplotype marker set in 2 previously reported pedigrees 


\begin{tabular}{|c|c|c|c|c|c|c|c|c|}
\hline \multirow{2}{*}{$\begin{array}{l}\text { Table } 1 \\
\text { Patient }\end{array}$} & \multicolumn{8}{|c|}{ Clinicopathologic, biochemical, and genetic features of newly reported and previously published adults with RNASEH1-related mitochondrial disease } \\
\hline & Clinical features & $\begin{array}{l}\text { Age at } \\
\text { onset, } y\end{array}$ & Brain CT/MRI & NCS/EMG & $\begin{array}{l}\text { Skeletal muscle } \\
\text { histochemistry }\end{array}$ & RCEA & $\begin{array}{l}\text { Multiple } \\
\text { mtDNA } \\
\text { deletions }\end{array}$ & $\begin{array}{l}\text { RNASEH1 cDNA and amino } \\
\text { acid change }\end{array}$ \\
\hline A-III.8 & $\begin{array}{l}\text { PEO, ptosis, facial weakness, proximal muscle } \\
\text { weakness }\end{array}$ & 33 & Normal & Myopathy & $\begin{array}{l}\text { RRFs, COX-deficient } \\
\text { fibers }\end{array}$ & ND & Y & $\begin{array}{l}\text { c. } 424 \mathrm{G}>\text { A p.Val142lle; } \\
\text { c.424G }>\text { A p.Val142lle }\end{array}$ \\
\hline A-III.9 & PEO, ptosis & 32 & ND & ND & RRFs & ND & ND & $\begin{array}{l}\text { c. } 424 \mathrm{G}>\text { A p.Val142lle; } \\
\text { c.424G }>\text { A p.Val142lle }\end{array}$ \\
\hline A-1II.10 & PEO, ptosis & ND & ND & ND & ND & ND & ND & $\begin{array}{l}\text { c.424G }>\text { A p.Val142lle; } \\
\text { c.424G }>\text { A p.Val142lle }\end{array}$ \\
\hline A-III.11 & PEO, ptosis & ND & ND & ND & ND & ND & ND & $\begin{array}{l}\text { c.424G }>\text { A p.Val142lle; } \\
\text { c.424G }>\text { A p.Val142lle }\end{array}$ \\
\hline B-II.1 & $\begin{array}{l}\text { PEO, ptosis, ataxia, facial and proximal muscle } \\
\text { weakness }\end{array}$ & 36 & Cerebral/cerebellar atrophy & ND & $\begin{array}{l}\text { SDH-positive/COX- } \\
\text { deficient fibers }\end{array}$ & ND & $\mathrm{Y}$ & $\begin{array}{l}\text { c.424G }>\text { A p.Val142lle; } \\
\text { c.424G }>\text { A p.Val142lle }\end{array}$ \\
\hline B-1I.8 & $\begin{array}{l}\text { PEO, ptosis, dysarthria, ataxia, facial and } \\
\text { proximal muscle weakness }\end{array}$ & 33 & Cerebral/cerebellar atrophy & $\begin{array}{l}\text { Sensory > motor neuronopathy } \\
\text { and myopathy }\end{array}$ & $\begin{array}{l}\text { RRFs, SDH-positivel } \\
\text { COX-deficient fibers, } \\
\text { neurogenic changes }\end{array}$ & Normal & $\mathrm{Y}$ & $\begin{array}{l}\text { c.424G }>\text { A p.Val142lle; } \\
\text { c.424G }>\text { A p.Val142lle }\end{array}$ \\
\hline C-II.1 & $\begin{array}{l}\text { PEO, ptosis, proximal muscle weakness, ataxia, } \\
\text { diabetes }\end{array}$ & 13 & ND & Sensory neuropathy & RRFs & ND & $\mathrm{Y}$ & $\begin{array}{l}\text { c. } 424 \mathrm{G}>\text { A p.Val142lle; } \\
\text { c.442T }>\text { C p.Cys148Arg }\end{array}$ \\
\hline$S 1^{2}$ & $\begin{array}{l}\text { PEO, ptosis, dysphagia, muscle pain, exercise } \\
\text { intolerance, respiratory and lower limb } \\
\text { weakness, ataxia }\end{array}$ & 20 & Cerebellar/brain stem atrophy & $\begin{array}{l}\text { Mild demyelinating motor } \\
\text { neuropathy and myopathy }\end{array}$ & $\begin{array}{l}\text { RRFs, COX-deficient } \\
\text { fibers }\end{array}$ & Low I/IV & Y & $\begin{array}{l}\text { c. } 424 \mathrm{G}>\text { A p.Val142lle; } \\
\text { c.469C }>\text { T p.Arg157* }\end{array}$ \\
\hline$s 2^{2}$ & $\begin{array}{l}\text { PEO, ptosis, limb and axial weakness, head } \\
\text { drop, pyramidal features dysphagia, reduced } \\
\text { visual acuity, cerebellar signs }\end{array}$ & 23 & ND & Mild neurogenic features & $\begin{array}{l}\text { RRFs, COX-deficient } \\
\text { fibers }\end{array}$ & Low I/IV & Y & $\begin{array}{l}\text { c. } 554 \mathrm{C}>\text { T p.Ala185Val; } \\
\text { c.424G }>\text { A p.Val142lle }\end{array}$ \\
\hline $\mathrm{S}^{2}{ }^{2}$ & PEO, dysphagia, respiratory impairment & ND & ND & ND & ND & ND & Y & $\begin{array}{l}\text { c. } 424 \mathrm{G}>\text { A p.Val142lle; } \\
\text { c.424G }>\text { A p.Val142lle }\end{array}$ \\
\hline$S 4^{2}$ & PEO, dysphagia, respiratory impairment & ND & ND & ND & ND & ND & Y & $\begin{array}{l}\text { c. } 424 \mathrm{G}>\text { A p.Val142lle; } \\
\text { c.424G }>\text { A p.Val142lle }\end{array}$ \\
\hline$S 5^{2}$ & $\begin{array}{l}\text { PEO, ptosis, dysphonia, dysphagia, pyramidal } \\
\text { signs, cerebellar signs, cognitive impairment }\end{array}$ & 45 & $\begin{array}{l}\text { Cerebellar/cortical atrophy, } \\
\text { deep periventricular white } \\
\text { matter hyperintensities }\end{array}$ & Neurogenic features & $\begin{array}{l}\text { RRFs, COX-deficient } \\
\text { fibers }\end{array}$ & ND & ND & $\begin{array}{l}\text { c.424G }>\text { A p.Val142lle; } \\
\text { c.424G }>\text { A p.Val142lle }\end{array}$ \\
\hline $56^{2}$ & $\begin{array}{l}\text { PEO, gait instability, severe dysphagia, } \\
\text { respiratory impairment }\end{array}$ & 40 & ND & ND & $\begin{array}{l}\text { RRFs, COX-deficient } \\
\text { fibers }\end{array}$ & ND & $\mathrm{Y}$ & $\begin{array}{l}\text { c.424G }>\text { A p.Val142lle; } \\
\text { c.424G }>\text { A p.Val142lle }\end{array}$ \\
\hline $1019^{7}$ & Bilateral ptosis, PEO, ataxia, fatigue, dysphagia & 44 & ND & ND & $\begin{array}{l}\text { RRFs, COX-deficient } \\
\text { fibers }\end{array}$ & ND & ND & $\begin{array}{l}\text { c.424G }>\text { A p.Val142lle; } \\
\text { c.442T>C p.Cys148Arg }\end{array}$ \\
\hline
\end{tabular}

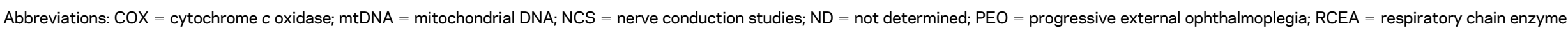
analysis; RRF = ragged red fiber; $\mathrm{SDH}=$ succinate dehydrogenase.

Families A, B, and C reported in the current study; $\mathrm{S} 1-6^{2}$ and $1019^{7}$ are previously published patients. 
Figure 2 Principal component and haplotype analysis of families harboring c.424G > A p.Val142lle variant and schematic illustrating the newly identified and previously reported RNASEH1 mutations to date

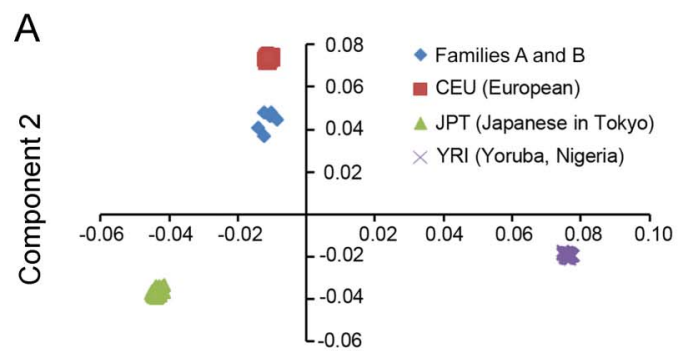

Component 1

\begin{tabular}{|c|c|c|c|c|c|c|c|c|c|c|c|}
\hline \multirow{3}{*}{$\begin{array}{l}\text { Marker } \\
\text { rs4971514 } \\
\text { rs11548215 }\end{array}$} & \multirow{2}{*}{$\begin{array}{c}\text { Chr. } \\
\text { position } \\
3469463\end{array}$} & \multicolumn{2}{|c|}{ A-III.8 } & \multicolumn{2}{|c|}{ B-II.8 } & \multicolumn{2}{|c|}{ C-II.1 } & \multicolumn{2}{|c|}{ s1 } & \multicolumn{2}{|c|}{ S3 } \\
\hline & & 1 & 1 & 1 & 0 & $(0 / 1$ & $(0 / 1)$ & $(0 / 1)$ & $(0 / 1)$ & 1 & 1 \\
\hline & 3481531 & 0 & 0 & 0 & 0 & 0 & 0 & 0 & 0 & 0 & 0 \\
\hline rs10186193 & 3597974 & 1 & 1 & 1 & 1 & 1 & 1 & 0 & 0 & 0 & 0 \\
\hline c. $424 G>A$ & 3598048 & 1 & 1 & 1 & 1 & 1 & 0 & 1 & 0 & 1 & 1 \\
\hline rs6712141 & 6990033 & 0 & 1 & 0 & 0 & 0 & 0 & 0 & 0 & 0 & 0 \\
\hline rs364891 & 7137067 & 1 & 1 & 1 & 1 & 1 & 1 & $(0 / 1)$ & $(0 / 1)$ & 1 & 1 \\
\hline rs309325 & 7154632 & 1 & 1 & 1 & 1 & 1 & 1 & 0 & 0 & 0 & 0 \\
\hline
\end{tabular}

B

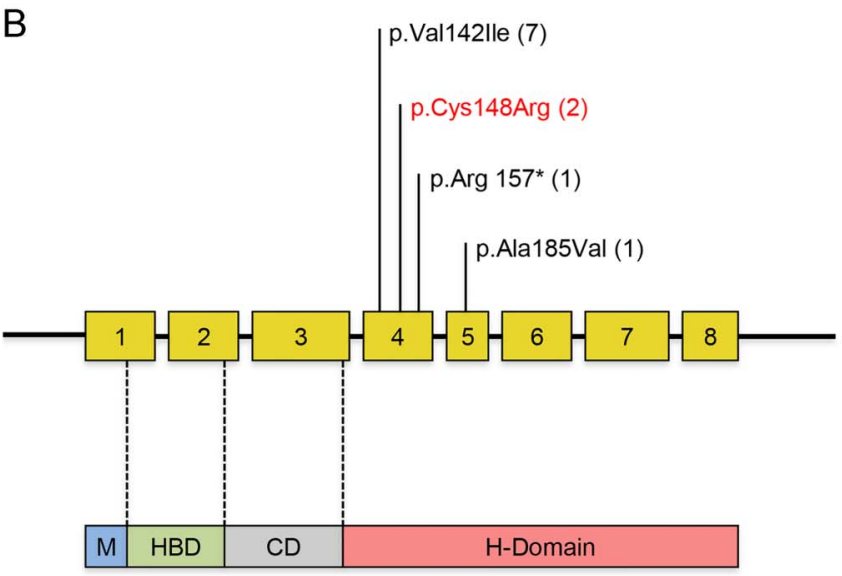

(A) Principal component analysis (top panel). $\mathrm{X}$-axis represents component 1; Y-axis represents component 2. Families $A$ and $B$ cluster to the same ethnic group. Haplotype analysis of individuals harboring the RNASEH1 mutation c.424G > A p.Val142lle (bottom panel). "1" indicates the presence of the marker, " $O$ " indicates the absence of the marker, and " $0 / 1$ " is used when haplotype could not be phased. Haplotypes reported are for A-III.8, B-II.8, C-II.1, $\mathrm{S}-1$, and S-3. Green = c.424G $>$ A mutation; gray = markers differing from reference haplotype. Families A and B shared a haplotype of at least 3.57 Mb. However, 2 additional haplotypes were different, suggesting distant recombination events or that the haplotypes arose independently. (B) The RNASEH1 gene has 8 exons encoding 4 protein domains as follows: mitochondrial targeting sequencing domain (M), hybrid-binding domain (HBD), connection domain (CD), and ribonuclease $\mathrm{H}$ domain ( $\mathrm{H}$-domain). The latter conducts all catalytic activity. Both herein newly identified and previously reported mutations are illustrated in the schematic. To date, all affected individuals harbor the "common" c.424G $>$ A p.Val142lle mutation either in homozygous or heterozygous states. Brackets = number of families with each mutation. Red $=$ newly reported variant.

with European ancestry (S1 and S3) revealed a different haplotype at single nucleotide polymorphism rs 10186193,74 base pairs away from the c.424G $>$ A p.Val142Ile mutation. These data are consistent with an independent origin for the c.424G $>$ A p.Val142Ile mutation in the patients analyzed.

DISCUSSION Based on data obtained from patients referred to the London and Oxford NHS England nationally commissioned service for mitochondrial diseases, RNASEH1 mutations represent the fourth most common cause of mendelian PEO associated with multiple mtDNA deletions in adults $(2.7 \%, 3 /$ 109), following mutations in POLG $(24.7 \%, 27 /$ 109), $R R M 2 B(16.5 \%, 18 / 109)$, and TWNK (also known as C10orf2, PEO1, or Twinkle, 16.5\%, 18/ 109). Additional, but less frequent, causes of adult mendelian PEO associated with multiple mtDNA deletions in our cohort include SLC25A4 (ANT1), OPA1, MFN2, TYMP, TK2, and SPG7 (1/109, 0.9\%), while $A F G 3 L 2, D N A 2, M G M E 1, P O L G 2$, $D G U O K$, and $M P V 17$ were not detected.

Two families, in whom affected individuals harbored multiple mtDNA deletions, were homozygous for the previously reported c.424G $>$ A p.Val142Ile mutation, thus confirming its pathogenicity and the importance of RNase $\mathrm{H} 1$ in mtDNA maintenance. A third proband was compound heterozygous with a novel missense mutation c. $442 \mathrm{~T}>\mathrm{C}$ p.Cys $148 \mathrm{Arg}$ in a highly conserved region of the enzyme, resulting in a hydrophobic amino acid being replaced by a positively charged residue within the RNase $\mathrm{H} 1$ active site. This mutation was previously reported as a variant of unknown significance in a patient with PEO harboring the POLG2 variant c. $1105 \mathrm{~A}>\mathrm{G}$ p.Arg369Gly, which was favored as being causative. ${ }^{7}$ However, a minor allele frequency of 0.003 suggests that the POLG2 variant c. $1105 \mathrm{~A}>\mathrm{G}$ p.Arg369Gly is a benign polymorphism and unlikely to be deleterious. ${ }^{8}$ Furthermore, the similarity in clinical phenotypes and association with identical mutations in our cohort supports the pathogenic basis of RNASEH1 c. $442 \mathrm{~T}>\mathrm{C}$ p.Cys $148 \mathrm{Arg}$ when a second mutant allele is present.

Clinically, RNASEH1-linked mitochondrial disease is relatively homogenous, comprising PEO, cerebellar ataxia, dysphagia, and proximal muscle weakness. This could reflect similar structural and functional consequences of the reported RNASEH1 mutations. Indeed, all patients are homozygous or heterozygous for c. $424 \mathrm{G}>\mathrm{A}$ p.Val142Ile, and remaining variants all occur within in the same catalytic domain (figure 2B). Additional deleterious mutations associated with more severe, early-onset clinical phenotypes might exist. However, we did not identify any cases in our mtDNA depletion cohort. Furthermore, it is possible that very detrimental mutations are embryonic lethal as is seen in knockout mice which are completely deficient in RNase H1. ${ }^{4}$ Finally, sensory ataxic neuropathy, previously unreported with RNASEH1 mutations, expands the recognized clinical phenotype to include ataxia neuropathy spectrum, most commonly associated with recessive POLG mutations. ${ }^{9}$

IBD analysis confirmed that families A and B were distantly related. However, their haplotype 
differed from 2 previously reported European pedigrees. $^{2}$ These data suggest that the c. $424 \mathrm{G}>\mathrm{A}$ p.Val142Ile mutation has arisen independently in the lineages analyzed. European admixing of the London-Oxford Indian families harboring c. $424 \mathrm{G}>\mathrm{A}$ p.Val142Ile could account for the lack of RNASEH1 mutations in the 50 additional Indian probands screened. Furthermore, the close proximity of all 3 families to the CEU (European) HapMap project populations (figure $2 \mathrm{~A}$ ) suggests that they belong to the Ancestral North Indian gene pool, which shares up to $70 \%$ genetic affinities with Europeans. ${ }^{10}$

Our data confirm that RNASEH1 mutations are an important cause of mitochondrial disease resulting from the secondary accumulation of multiple mtDNA deletions and that the phenotypic spectrum in adults is relatively benign. Nevertheless, RNASEH1 genetic analysis should be considered in all patients presenting with ataxia neuropathy spectrum once POLG mutations have been excluded. Finally, although the commonly occurring c.424G $>$ A p.Val142Ile RNASEH1 variant could indicate a mutation hotspot within the gene, it might instead reflect an inability of the mutant enzyme to bind with a partner protein, thereby allowing Val142Ile RNase H1 to attack its substrates indiscriminately. ${ }^{6}$ As such, loss-of-function mutations could confer different clinical phenotypes.

\section{AUTHOR CONTRIBUTIONS}

Enrico Bugiardini: study design, analysis and interpretation of data, and drafting the manuscript. Olivia V. Poole: analysis and interpretation of data and revising the manuscript. Andreea Manole: acquisition, analysis and interpretation of data, and revising the manuscript. Alan M. Pittman, Alejandro Horga, Iain Hargreaves, Cathy E. Woodward, Mary G. Sweeney, Janice L. Holton, Jan-Willem Taanman, and Gordon T. Plant: acquisition, analysis and interpretation of data, and revising the manuscript. Joanna Poulton: study concept, acquisition of data, and revising the manuscript. Massimo Zeviani, Daniele Ghezzi, John Taylor, and Conrad Smith: acquisition and interpretation of data and revising the manuscript. Carl Fratter: study design, acquisition and interpretation of data, and revising the manuscript. Meena A. Kanikannan and Arumugam Paramasivam: acquisition and interpretation of data and revising the manuscript. Kumarasamy Thangaraj: study concept, acquisition and interpretation of data, and revising the manuscript. Antonella Spinazzola, Ian J. Holt, and Henry Houlden: study concept and revising the manuscript. Michael G. Hanna: study concept, interpretation of data, and revising the manuscript. Robert D.S. Pitceathly: study design, analysis and interpretation of data, and drafting the manuscript.

\section{ACKNOWLEDGMENT}

The authors acknowledge the Telethon-Italy Network of Genetic Biobanks (GTB12001J) for DNA supply.

\section{STUDY FUNDING}

The research leading to these results has received funding from the European Community's Seventh Framework Programme (FP7/2007-2013) under grant agreement no. 2012-305121 "Integrated European—omics research project for diagnosis and therapy in rare neuromuscular and neurodegenerative diseases (NEUROMICS)." This work is also supported by a Medical Research Council Centre grant (G0601943) and Wellcome Trust grant on Synaptopathies. Part of this work was undertaken in the University College London Hospitals/University College London
Institute of Neurology sequencing facility, which received a proportion of funding from the Department of Health's National Institute for Health Research Biomedical Research Centres funding scheme. R.D.S.P. is funded by the National Institute for Health Research. O.V.P. has received funding from the Lily Foundation. J.P. receives support from the Lily Foundation, NewLife (SG/14-15/11), the Medical Research Council (MR/J010448/1), and the Wellcome Trust (0948685/Z/10/Z). K.T. is supported by the Department of Biotechnology and the Council of Scientific and Industrial Research (BioAge: BSC0118), Government of India. A.P. is supported by the Science and Engineering Research Board (PDF/2016/000881), Government of India. A.S. is supported by the Medical Research Council Senior Non-Clinical Fellowship, MC_PC_13029.

\section{DISCLOSURE}

Enrico Bugiardini, Olivia V. Poole, Andreea Manole, Alan M. Pittman, Alejandro Horga, Iain Hargreaves, Cathy E. Woodward, and Mary G. Sweeney report no disclosures. Janice L. Holton has received travel funding from Merck-Serono; has served on the editorial board of Neuropathology and Applied Neurobiology; has been an employee of University College London; and has received research support from Alzheimer's Research Trust, The Margaret Watson Memorial Trust Grant from The Sarah Matheson Trust, Action Medical Research, Brain Net Europe: Support for the Queen Square Brain Bank for Neurological Disorders, The Sarah Matheson Trust, Myositis Support Group, The Multiple System Atrophy Trust, the Michael J Fox Foundation for Parkinson's Research, Alzheimer's Research UK, MSA Coalition, and the King Baudouin Foundation Sophia Fund. Jan-Willem Taanman has served on the scientific advisory board of Novintum Bioscience Ltd.; has received research support from Royal Free Charity; and receives royalty payments from the University of Oregon. Gordon T. Plant has served on the editorial board of Neuro-Ophthalmology. Joanna Poulton and Massimo Zeviani report no disclosures. Daniele Ghezzi has served on the editorial board of Orphanet Journal of Rare Diseases and has received research support from the Italian Ministry of Health, European Communities, Foundation Telethon, CARIPLO Foundation Italy, and the Pierfranco and Luisa Mariani Foundation of Italy. John Taylor, Conrad Smith, Carl Fratter, and Meena A. Kanikannan report no disclosures. Arumugam Paramasivam has received research support from DST-SERB National Post Doctoral Fellowship No.: PDF/2016/000881. Kumarasamy Thangaraj has served on the editorial boards of Mitochondrion, PLoS One, BMC Medical Genetics, Scientific Reports, and Clinical Genetics. Antonella Spinazzola reports no disclosures. Ian J. Holt has received research support from Medical Research Council UK. Henry Houlden has received research support from The Medical Research Council (MRC) UK, The BRT, The MDA USA, Muscular Dystrophy UK, Ataxia UK, Muscular Dystrophy UK, Rosetrees Trust, The Wellcome Trust, and the National Institute for Health (NIHR). Michael G. Hanna has been a consultant for Novartis and has received research support from an MRC Centre Grant and the Myositis Support Group. Robert D.S. Pitceathly reports no disclosures. Go to Neurology.org/ng for full disclosure forms.

Received December 19, 2016. Accepted in final form March 13, 2017.

\section{REFERENCES}

1. DiMauro S, Schon EA, Carelli V, Hirano M. The clinical maze of mitochondrial neurology. Nat Rev Neurol 2013; 9:429-444.

2. Reyes A, Melchionda L, Nasca A, et al. RNASEH1 mutations impair mtDNA replication and cause adult-onset mitochondrial encephalomyopathy. Am J Hum Genet 2015;97:186-193.

3. Keller W, Crouch R. Degradation of DNA RNA hybrids by ribonuclease $\mathrm{H}$ and DNA polymerases of cellular and viral origin. Proc Natl Acad Sci USA 1972;69:3360-3364.

4. Cerritelli SM, Frolova EG, Feng C, Grinberg A, Love PE, Crouch RJ. Failure to produce mitochondrial DNA results in embryonic lethality in Rnaseh1 null mice. Mol Cell 2003;11:807-815. 
5. Holmes JB, Akman G, Wood SR, et al. Primer retention owing to the absence of RNase $\mathrm{H} 1$ is catastrophic for mitochondrial DNA replication. Proc Natl Acad Sci USA 2015; 112:9334-9339.

6. Akman G, Desai R, Bailey LJ, et al. Pathological ribonuclease H1 causes R-loop depletion and aberrant DNA segregation in mitochondria. Proc Natl Acad Sci USA 2016;113:E4276-E4285.

7. Lieber DS, Calvo SE, Shanahan K, et al. Targeted exome sequencing of suspected mitochondrial disorders. Neurology 2013;80:1762-1770.
8. Lek M, Karczewski KJ, Minikel EV, et al. Analysis of protein-coding genetic variation in 60,706 humans. Nature 2016;536:285-291.

9. Lax NZ, Whittaker RG, Hepplewhite PD, et al. Sensory neuronopathy in patients harbouring recessive polymerase gamma mutations. Brain 2012;135: 62-71.

10. Metspalu M, Romero IG, Yunusbayev B, et al. Shared and unique components of human population structure and genome-wide signals of positive selection in South Asia. Am J Hum Genet 2011;89:731-744. 


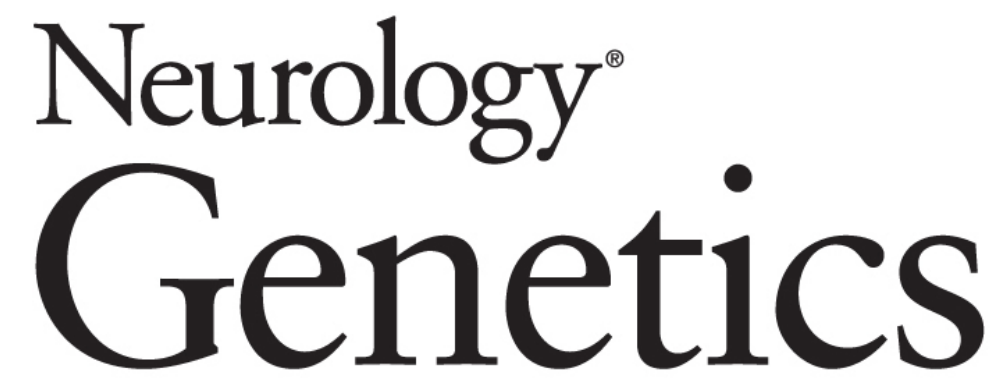

Clinicopathologic and molecular spectrum of RNASEH1-related mitochondrial disease Enrico Bugiardini, Olivia V. Poole, Andreea Manole, et al.

Neurol Genet 2017;3;

DOI 10.1212/NXG.0000000000000149

This information is current as of May 2, 2017

Neurol Genet is an official journal of the American Academy of Neurology. Published since April 2015, it is an open-access, online-only, continuous publication journal. Copyright Copyright $\odot 2017$ The Author(s).

Published by Wolters Kluwer Health, Inc. on behalf of the American Academy of Neurology.. All rights reserved. Online ISSN: 2376-7839.

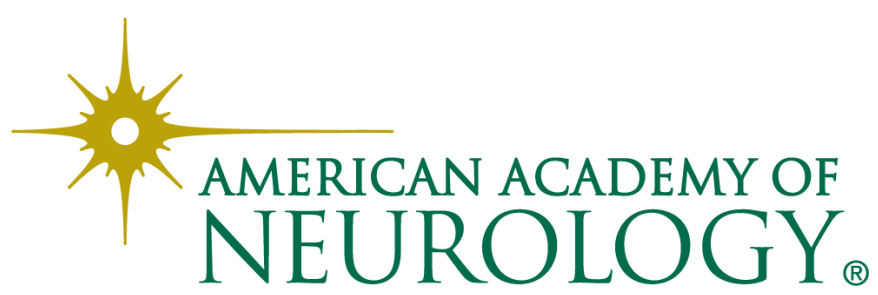




\section{Updated Information \& Services}

\section{Supplementary Material}

\section{References}

Citations

Subspecialty Collections

Permissions \& Licensing

Reprints including high resolution figures, can be found at: http://ng.neurology.org/content/3/3/e149.full.html

Supplementary material can be found at: http://ng.neurology.org/content/suppl/2017/05/02/3.3.e149.DC1

This article cites 10 articles, 3 of which you can access for free at: http://ng.neurology.org/content/3/3/e149.full.html\#\#ref-list-1

This article has been cited by 1 HighWire-hosted articles: http://ng.neurology.org/content/3/3/e149.full.html\#\#otherarticles

This article, along with others on similar topics, appears in the following collection(s):

\section{Cerebellum}

http://ng.neurology.org//cgi/collection/cerebellum

\section{Mitochondrial disorders}

http://ng.neurology.org//cgi/collection/mitochondrial_disorders

Muscle disease

http://ng.neurology.org//cgi/collection/muscle_disease

Ocular motility

http://ng.neurology.org//cgi/collection/ocular_motility

\section{Peripheral neuropathy}

http://ng.neurology.org//cgi/collection/peripheral_neuropathy

Information about reproducing this article in parts (figures,tables) or in its entirety can be found online at:

http://ng.neurology.org/misc/about.xhtml\#permissions

Information about ordering reprints can be found online: http://ng.neurology.org/misc/addir.xhtml\#reprintsus

Neurol Genet is an official journal of the American Academy of Neurology. Published since April 2015, it is an open-access, online-only, continuous publication journal. Copyright Copyright $\odot 2017$ The Author(s). Published by Wolters Kluwer Health, Inc. on behalf of the American Academy of Neurology.. All rights reserved. Online ISSN: 2376-7839.

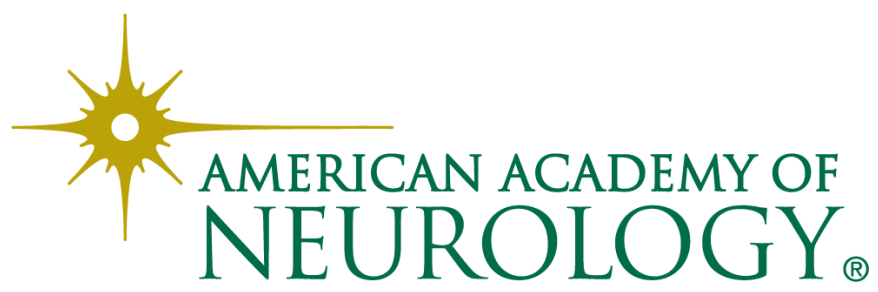

